\title{
MASCULINIDADE, AUTOIMAGEM E PRECONCEITO EM REPRESENTAÇÕES SOCIAIS DE HOMOSSEXUAIS
} MASCULINITY, SELF-IMAGE AND PREJUDICE IN SOCIAL REPRESENTATIONS OF HOMOSEXUALS

\author{
Recebido em 12.07.2014. Aprovado em 12.04.2015 \\ Avaliado pelo sistema double blind review \\ http://dx.doi.org/10.12712/rpca.v9i1.465
}

\section{Claudia Sirangelo Eccel}

claudiaeccel@hotmail.com

Universidade Petrobras do Petróleo Brasileiro S/A

Rio de Janeiro - RJ- Brasil

\section{Luiz Alex Silva Saraiva}

saraiva@face.ufmg.br

Universidade Federal de Minas Gerais

Belo Horizonte - MG - Brasil

\section{Alexandre de Pádua Carrieri \\ alexandre@face.ufmg.br \\ Universidade Federal de Minas Gerais \\ Belo Horizonte - MG - Brasil}

\section{Resumo}

Neste artigo o objetivo é investigar como gays representam a si próprios, sua própria masculinidade, e os outros homossexuais nas suas relações sociais cotidianas, o que se estende ao meio organizacional. Pressupomos que ocorre a reprodução de representações de masculinidades hegemônicas e subordinadas em tais relações. A metodologia adotada é qualitativa, sendo este estudo exploratório de características descritivas. Foram entrevistados individualmente 13 homossexuais masculinos, buscando apreender suas histórias de vida. Os resultados sugerem que a masculinidade é ambígua, pois os entrevistados se representam como "mais homens" do que outros gays efeminados, ratificando uma espécie de reprodução social da discriminação. As conclusões sugerem que as representações sociais são úteis não apenas por mapear como se sentem os gays, mas também como eles reagem a todo um aparato social de discriminação.

Palavras-Chave: Masculinidades. Auto-imagem. Preconceito. Homossexuais.

\section{Abstract}

In this paper we deal with na investigation about how gay men represent themselves, their own masculinity, and other gay men in their daily social relations, what also happens at organizational context. We suppose that it occurs reproduction of hegemonic and subordinated masculinity representations in those relations. Methodological approach is qualitative, in an exploratory and descriptive study. We interviewed individually 13 gay men, seeking apprehend their life stories. Main results suggest that masculinity is ambiguous, because interviewees represented themselves as "more men" than other effeminate gay men, confirming a kind of social reproduction of discrimination. Conclusions suggest that social representations are useful for mapping how gay men feel, and also how they react to the apparatus of social discrimination.

Keywords: Masculinities. Self-image. Prejudice. Homosexuals. 


\section{Introdução}

Neste artigo nos propomos a lançar um olhar sobre as relações de gênero na homossexualidade, pesquisando como os gays a negociam e a administram frente a um contexto heteronormativo, a fim de desvendar como operam as representações sociais de masculinidade, a autoimagem e o preconceito entre os homens homossexuais. Embora Eccel e Flores-Pereira (2008) tenham feito considerações pertinentes entre as diferenças entre os termos homossexual e gay, neste artigo tomá-los-emos como sinônimos, a fim de evitar a repetição demasiada de um ou outro termo. Como lidamos com um conceito polissêmico construído socialmente, interessa-nos investigar como gays representam a si próprios, sua própria masculinidade, e os outros homossexuais nas suas relações sociais cotidianas, o que se estende ao meio organizacional. Pressupomos que ocorre a reprodução de representações de masculinidades hegemônicas e subordinadas em tais relações.

Na área da Administração, a homossexualidade tornou-se tema de pesquisas recentemente, em geral integrando os estudos sobre a diversidade, que enfocam a inserção de mulheres, pessoas com deficiência, homossexuais, e de diferentes etnias no mercado de trabalho. No tocante aos homossexuais, nos últimos anos tem havido interesse sobre sua inserção e estratégias de sobrevivência no mercado de trabalho, como atestam, por exemplo, os estudos de Caproni Neto et al. (2014), Carrieri, Souza e Aguiar (2014), Bastos, Pinheiro e Lima (2013), Carrieri, Aguiar e Diniz (2013), Diniz et al. (2013), Bicalho e Caproni Neto (2012), Saraiva (2011), Irigaray (2010), Irigaray, Saraiva e Carrieri (2010), Bicalho e Diniz (2009), Siqueira et al. (2009), Eccel e FloresPereira (2008), Irigaray (2007), Siqueira e Zauli-Fellows (2006).

A homossexualidade começou a ser estudada no século XIX por higienistas que buscavam propor medidas sanitárias e repressivas, e, a partir da descoberta do vírus HIV, houve crescimento dos estudos na Medicina, especialmente na década de 1990. Além disso, é uma temática recorrente na Psicologia, Antropologia, História, Sociologia, Artes e Literatura, e, aos poucos, observa-se que visão preconceituosa inicial passou a dar lugar a estudos sobre significados sociais associados ao homoerotismo, estratégias individuais e coletivas para lidar com preconceitos e outros aspectos (GÓIS, 2004). Atualmente é também possível encontrar estudos na Educação (LOURO, 2000; SANTOS, 2004; SEFFNER, 2003), Sociologia (PARKER, 2004), Antropologia (PEREIRA, 2004).

Na Administração, além de ganhar espaço nos estudos sobre diversidade, a área de marketing tem se interessado pelo consumo de homossexuais, como um mercado ainda pouco explorado (PEREIRA; AYROSA; OJIMA, 2005; TIRELLI, 2006). Góis (2004) assevera que os estudos de gênero, por terem-se ocupado basicamente de mulheres, não abriram espaço para as questões gays e lésbicas, tornando-se este um campo, embora relevante, pouco estudado.

Após esta introdução, discutiremos teoricamente a polissemia da masculinidade como categoria teórica, mostrando que se trata de um conceito multifacetado, bem como as masculinidades homossexuais, o que precede a abordagem sobre as representações sociais e sua utilidade teórica e metodológica para o estudo. Em seguida, apresentaremos a metodologia que conduziu o estudo, a análise dos dados e as considerações finais do artigo.

\section{Masculinidades}

Na esteira do movimento feminista, os homens têm sido estudados pelas ciências sociais em especial a partir da década de 1990, quando esta linha de estudos teve origem nos Estados Unidos, tendo sido adotada mais adiante em outros países. A masculinidade, porém, havia sido "desnaturalizada" anteriormente por Bourdieu (1995), ao problematizar a dominação masculina como uma presença invisível no pensamento ocidental, da ciência ao senso comum. 


\section{Claudia Sirangelo Eccel, Luiz Alex Silva Saraiva e \\ Alexandre de Pádua Carrieri}

Este autor salienta que mesmo em sociedades tribais a masculinidade é tida como condição de superioridade, situando os sujeitos masculinos em posição de maior status social. A condição masculina, argumenta, é tão arraigada no pensamento ocidental que se tornou sinônimo de humanidade, assumindo caráter universal, o que acarretou que o pensamento científico fosse alicerçado em sujeitos masculinos.

A partir destes pressupostos, durante muitos anos os estudos de gênero dirigiram o olhar exclusivamente para as mulheres, tomando o masculino como uma totalidade homogênea e indiferenciada. As conseqüências desta postura teórica têm sido a manutenção da oposição binária entre homens e mulheres (CAPPELLE et al., 2006). Foi apenas a partir da década de 1990 que esta condição passou a ser questionada, especialmente por autores como Daniel Welzer-Lang e Robert W. Connell, que passaram a mostrar que existem desníveis de legitimação nas masculinidades, o que significa que há diversas maneiras diferentes de vivê-las e representá-las, as quais não são igualmente legitimadas e valorizadas.

No intuito de questionar a homogeneidade do masculino, Welzer-Lang (2004, p.117) propõe que o gênero masculino é, também, atravessado por relações sociais de sexo:

A problemática das relações sociais entre os sexos reifica e (re)naturaliza o gênero criando dois grupos distintos, percebidos como socialmente homogêneos e antagônicos (ou complementares, o que vem a dar no mesmo). 0 estudo concreto dos homens e do masculino mostra que os homens estão longe de ser um grupo ou uma classe homogênea, e que o que faz deles um grupo social ou uma classe (os privilégios atribuídos aos homens, a aspiração de se igualar aos homens, tidos como superiores, as representações e práticas comuns...), não é suficiente para dar conta das relações entre eles.

De acordo com este autor, entre os homens percebem-se relações hierárquicas que os situam em posições mais ou menos privilegiadas e, portanto, mais ou menos dominadas. Para ele, ainda que os homens sejam dominantes em relação às mulheres, há hierarquias masculinas que os organizam em termos dos privilégios e poder que detêm. Ou seja, nem todos os homens são igualmente dominantes, uns o são tanto em relação às mulheres quanto em relação a outros homens. 0 autor traz a noção de "grande homem" os que possuem poder "político, religioso (ou mágico), econômico, bélico, administrativo, científico, universitário etc." (WELZER-LANG, 2004, p. 123), que influenciam os privilégios que estes homens obtêm em suas relações com os outros homens e também com as mulheres.

A noção de superioridade masculina sobre as mulheres, assim, simultaneamente impõe regras aos homens, pois configura a sexualidade masculina como andro-heterocentrada e homofóbica, ou seja, o homem dito "normal" - que poderá requerer o status de "homem de verdade" e seus privilégios de gênero - deve ser viril, ativo e dominante. Os outros, com perfil distinto deste, são relegados aos grupos dominados, assim como as mulheres, crianças e todos os que diferem do "normal" (WELZER-LANG, 2004).

Connell pesquisa as masculinidades a fim de propor algumas mudanças nas relações de gênero na direção de uma maior justiça e igualdade social. No seu entendimento, a masculinidade é moldada na esfera da produção, de acordo com a classe, local de trabalho, ambiente político etc. E, no tocante à estrutura das relações de gênero, Connell (1995) salienta que além das interrelações entre homens e mulheres, as masculinidades abrangem a economia e o Estado, mostrando-se uma estrutura ampla e complexa. Para ele, diferentes masculinidades são produzidas em contextos distintos, mas também em um mesmo recorte social, sugerindo que não se trata de um conceito homogêneo (CONNELL, 1995). Assim como Welzer-Lang (2004) aqui também as relações de gênero incluem as relações entre os homens, suas dominações, exclusões e alianças. Em torno de uma masculinidade tida como hegemônica, ou seja, 


\section{MASCULINIDADE, AUTOIMAGEM E PRECONCEITO EM REPRESENTAÇÕES SOCIAIS DE HOMOSSEXUAIS}

reconhecida como dominante, há outras masculinidades periféricas, menos reconhecidas, menos legitimadas e, conseqüentemente, menos dominantes.

Para Connell (1998), não se deve pensar em masculinidade como algo homogêneo, visto que se trata de um conceito plural, configurado de forma diferenciada por diferentes culturas e períodos históricos, possibilitando, assim, que mesmo dentro de um mesmo recorte cultural coexistem masculinidades diversas. As masculinidades são, ainda, sustentadas coletivamente por grupos e instituições, que podem produzir simultaneamente diferentes masculinidades e organizar as relações hierárquicas entre as mesmas, sendo passíveis de mudanças e reconstruções. Dessa forma, embora remetam a um corpo biologicamente masculino, a construção e vivência das masculinidades ultrapassam a predeterminação física, uma vez que os corpos masculinos são construídos, definidos e disciplinados especificamente conforme o contexto. As masculinidades são, neste sentido, ativamente produzidas com base nos recursos e nas estratégias disponíveis em determinada cultura (CONNELL, 1998).

Outro aspecto ressaltado por Connell (1998) é a relação de hierarquia e hegemonia ente as masculinidades. Por coexistirem diversas masculinidades, operam entre estas relações sociais de hierarquia e exclusão, e em cada contexto, há uma (ou mais de uma) forma de masculinidade privilegiada ou desejada, que pode não ser a mais comum numericamente, mas é a mais legitimada e aceita. A dominância da masculinidade hegemônica se sobressai pela desvalorização daquilo que é diferente, e pode ser exercia de modo implícito, ou mesmo violento.

Cada cultura produz expectativas de condutas para homens e mulheres, que são estimuladas e ensinadas pelas diversas instituições sociais, como a família, a escola, a mídia, e ambiente de trabalho. Por meio da educação alguns comportamentos são valorizados ou extintos de acordo com a sua significação. De acordo com Louro (2000), a identidade masculina ao mesmo tempo em que é aquela mais legitimada, também é a mais controlada e vigiada nos primeiros anos de vida, tanto na família quanto na escola, onde se realiza: "um investimento continuado e cuidadoso de garantir a 'aquisição' da heterossexualidade” (p. 69). Além disso, as práticas pedagógicas direcionam e delimitam comportamentos masculinos ou femininos tidos como adequados para as crianças. 0 mesmo se dá nas aulas de educação física nas escolas, onde as atividades são direcionadas conforme o sexo dos alunos: meninos jogam futebol e meninas dançam (OLIVEIRA, DUARTE, 2006).

Entretanto, esta convenção faz uso de uma determinada forma de masculinidade para definir uma dita masculinidade geral, criando um totalitarismo de gênero, que despreza, ao ignorar, outras formas. Pensar as masculinidades hegemônicas e os estilos de vida considerados desviantes remete a uma questão anterior que é o binarismo normal-desviante, visto que o normal e o desviante são noções construídas a partir dos significados atribuídos contextualmente. As masculinidades hegemônicas não têm sido questionadas, e é importante ressaltar que estas identidades não problematizadas e de que não se fala, para usar as palavras de Louro (2000), cristalizam-se como a norma aceita. Para esta autora, é necessário pensar politicamente as identidades de gênero, pois algumas identidades, como a masculina branca, são vistas como “tão 'normais' que não precisam dizer de si; enquanto outras se tornam 'marcadas' e, geralmente, não podem falar por si" (LOURO, 2000, p. 67), como no caso dos homossexuais (grifos do autor).

\section{Masculinidades homossexuais}

A masculinidade hegemônica está profundamente associada a aspectos de autoridade, domínio técnico e financeiro, agressividade e interesses heterossexuais (CONNELL, 1998). As práticas sexuais são simultâneas e inseparáveis das práticas de gênero, e, em termos hegemônicos, as 


\section{Claudia Sirangelo Eccel, Luiz Alex Silva Saraiva e \\ Alexandre de Pádua Carrieri}

práticas sexuais masculinas associam-se à heterossexualidade e à dominância. A passividade e os comportamentos efeminados costumam ser desvalorizados e tachados como parte de uma masculinidade subordinada.

De acordo com Seffner (2003), na cultura ocidental contemporânea, o gênero e a sexualidade constituem-se categorias fundamentais para pensar a identidade do sujeito e, mais especificamente, é a partir da sexualidade que as construções identitárias se organizam (ROBICHAUD; DAVEL, 2002). Ou seja, a identidade sexual se sobrepõe a pertencimentos étnicos, sociais ou religiosos tornando-se definidora da identidade do indivíduo. A identidade sexual, portanto, coloca o sujeito em determinada posição, o que gera conseqüências políticas em termos da valorização associada culturalmente aos diferentes exercícios da sexualidade.

Em termos masculinos, o distanciamento da masculinidade hegemônica remete a desvios, que podem ser mais ou menos pronunciados, conforme os rompimentos que causam. Se a hegemonia está associada a uma vivência masculina heteronormativa, as identidades homossexuais ou bissexuais são compreendidas como desvios, "anormalidades" capazes de impor desafios específicos para estes sujeitos.

Acerca das identidades homossexuais, assim como já foi ressaltado sobre as masculinidades, não podemos pensar em categorias estanques. Há, entre as identidades homossexuais, diversas nuances no que diz respeito à vivência e demonstração da sexualidade. Seffner (2003) discute que nem todos os homens que praticam sexo com outros homens consideram-se homossexuais, em especial se paralelamente também tiverem práticas heterossexuais. Além disso, as vivências de sexualidade não podem ser separadas dos demais pertencimentos do sujeito. Rolnik (1996) argumenta que, em termos micropolíticos, é impossível pensar gênero segundo a lógica binária de oposição. A multiplicidade de configurações possíveis ultrapassa a diferença do masculino e feminino, criando multiplicidades e simultaneidades em vez de identidades rígidas. Desta maneira, não podemos opor também heterossexuais a homossexuais. Entre as vivências homossexuais de homens e mulheres há várias possibilidades, que não podem ser resumidas em identidades fixas.

Vale lembrar, ainda, uma vez que as masculinidades hegemônicas são pouco acessíveis, e que apenas um pequeno número de homens realmente possui todos os elementos que a constituem, que são inúmeros os que agem por imitação e legitimam os ideais mesmo quando neles não se enquadram (CONNELL, 1998). Seffner (2003) discute que não raras vezes se deparou com relatos de homens casados e bissexuais que se apóiam em traços da masculinidade hegemônica, como ser um bom pai um provedor do lar, um trabalhador, para contrabalançar seus possíveis "desvios". É a partir desta problematização que podemos pensar as reações homofóbicas de homens assumidamente homossexuais em relação a outros gays de comportamento efeminado.

Esta visão de homens gays a respeito de homens igualmente gays demonstra uma face do ideal de masculinidade e das maneiras como a auto-imagem é afetada pelas representações sociais da masculinidade hegemônica.

\section{Representações Sociais}

Desde que Moscovici (1997) ampliou o conceito de representações coletivas de Durkheim, as representações sociais têm sido usadas como referencial teórico de vários ramos de conhecimento. Oriundo da psicologia, este conceito logo se espraiou, pelas possibilidades analíticas que abre, fazendo hoje parte da agenda de pesquisa de distintas áreas de conhecimento, como, por exemplo, a Enfermagem (COSTA; CHAVES, 2004; LIMA JUNIOR; ÉSTHER, 2001), a Saúde Pública (HERZLICH, 2005; AZEVEDO, 2002), a Geografia (PELUSO, 2003), a sociologia (MATTOS; FERREIRA, 2004), e a Administração (SARAIVA; SILVEIRA, 2007; 
CAVEDON; FERRAZ, 2005), só para ficar em algumas.

As representações sociais se referem a um processo dinâmico, ao mesmo tempo psicológico e social, em que a realidade é "interpretada" e "traduzida" por meio do grupo de referência, implicando posicionamentos individuais sobre o objeto representado. Ao mesmo tempo, diz respeito a como o indivíduo percebe o mundo que o cerca, e como consegue, na interação com seus pares, influenciá-los e ser por eles influenciado nas formas de representar a realidade. É, assim, um conhecimento social, e, ao mesmo tempo, uma realidade psicológica (MOSCOVICI, 2007). Isso implica, conforme Mattos e Ferreira (2004), as representações sociais atuarem como organizadoras de condutas e comunicações sociais, relacionando-se à questão do conhecimento, além de exercerem influência sobre a configuração das identidades pessoais e sociais. Assim, expressam que os indivíduos, em interação com o seu meio, na condição de pensadores, reelaborem informações e estabeleçam diálogos entre as esferas individual e social, construindo suas próprias representações e comunicando-as aos demais indivíduos, em um ciclo retroalimentado constantemente (CAVEDON; FERRAZ, 2005).

Assim, além de as representações sociais atuarem no nível cognitivo, função esta simultaneamente individual (o que conheço, aprendo, e percebo) e grupal (o que meu grupo de referência conhece, aprende, percebe), dizem respeito à esfera do comportamento social propriamente dito, pois a forma pela qual é representado um dado objeto implica respostas compatíveis no nível social. Isso significa além de representar o objeto, agir de acordo com as expectativas sociais do grupo de referência daquele que representa o objeto. Não quer dizer que as representações sejam uma espécie de camisa de força, e que os indivíduos sempre se comportarão de acordo com o que se espera ser uma resposta socialmente adequada para uma dada representação. Mas que os processos dinâmicos de socialização implicam ajustes, e estes mais freqüentemente se dão no sentido de o indivíduo buscar adequação ao seu contexto social de referência.

Todavia, precisa ficar claro, como defende Herzlich (2005), que tal processo não é mecânico e nem unilateral; as representações sociais se concretizam também em um outro sentido, em que o grupo recebe influências das esferas cognitivas individuais. Os indivíduos, dentro de suas diferenças, representam a realidade social de forma diferenciada, e levam tais distinções aos seus grupos de referência, influenciando a configuração do que é social nas representações.

No caso dos homens homossexuais, as representações sociais dizem muito a respeito da masculinidade. Em primeiro lugar, porque se referem à imagem - socialmente representada do masculino hegemônico, algo que, num contexto social qualquer, reflete o que se espera minimamente dos homens a fim de que sejam considerados como tal. Não se trata apenas de percepção do masculino, mas de ajustamentos diversos no sentido de procurar pertencer ao grupo que possui hegemonia da masculinidade. Estes ajustamentos levam ao segundo elemento: as representações sociais também se referem à autoimagem, uma vez que os indivíduos representam a si próprios em relação a um ideal de masculinidade em vigência na sociedade, ao qual, em muitos dos casos, buscam se ajustar, "sufocando-se", do ponto de vista simbólico, sacrificando o que é distintivo em termos identitários em nome de um padrão social hegemônico. Por fim, as representações sociais da masculinidade também dizem respeito ao preconceito, porque, em função o modelo predominante do masculino, os indivíduos projetam padrões sociais minimamente aceitáveis para si próprios e para os outros indivíduos, razão pela qual não é incomum que homossexuais discriminem outros homossexuais que apresentem masculinidades "desviantes", a exemplo dos efeminados, um grupo estigmatizado socialmente (IRIGARAY, 2007). 


\section{Claudia Sirangelo Eccel, Luiz Alex Silva Saraiva e \\ Alexandre de Pádua Carrieri}

\section{Metodologia}

A presente pesquisa - parte de uma tese de doutorado - buscou apreender histórias de vida de homens homossexuais, selecionados por acessibilidade, desde que atendessem ao critério de terem-se sentido assediados em algum momento ao longo de sua trajetória profissional. Um estudo baseado em histórias de vida tem foco na longitudinalidade dos dados, uma vez que não se trata de um momento pontual o foco do trabalho. Toda a ênfase em uma pesquisa desse tipo recai sobre o processo, e compreender como a história da vida do entrevistado ajuda a explicar suas posições a respeito da temática em foco. Os relatos dos entrevistados versaram sobre sua origem familiar, histórico pessoal e profissional, percepção da homossexualidade, relacionamentos, possibilidades de assumir-se gay frente a grupos de referência, como família, amigos e no trabalho, maneiras de lidar com a homossexualidade nas esferas pessoal e profissional, situações percebidas como assédio moral, gerenciamento e conseqüências destas.

Na cidade de Porto Alegre, foram realizadas 13 entrevistas com homens de 23 a 56 anos durante três meses. A caracterização destes sujeitos da pesquisa encontra-se no quadro 1. Nos depoimentos, chamou atenção que a maioria dos entrevistados se posicionava preconceituosamente em relação a outros homens homossexuais de postura efeminada, além das maneiras como constroem sua autoimagem. A partir disto, optamos por analisar mais detidamente estas questões, relacionadas às representações sociais de masculinidade.

\begin{tabular}{|c|c|c|}
\hline Entrevistado & Idade & Atuação profissional \\
\hline E1 & 27 anos & Comissário de bordo \\
\hline E2 & 37 anos & Comerciante \\
\hline E3 & 56 anos & Comerciante \\
\hline E4 & 31 anos & Administrador \\
\hline E5 & 51 anos & Funcionário público \\
\hline E6 & 59 anos & Professor aposentado \\
\hline E7 & 38 anos & Bancário \\
\hline E8 & 42 anos & Bancário \\
\hline E9 & 34 anos & Funcionário público \\
\hline E10 & 37 anos & Engenheiro \\
\hline E11 & 34 anos & Advogado \\
\hline E12 & 31 anos & Informata \\
\hline E13 & 23 anos & \\
\hline
\end{tabular}

Quadro 1 - Caracterização dos sujeitos da pesquisa

Fonte: Dados de pesquisa.

Este é um estudo exploratório com orientação qualitativa, que, de acordo com Víctora, Knauth e Hassen (2000), baseia-se no pressuposto de que a realidade não existe separadamente das percepções e significações atribuídas pelos sujeitos. Para Denzin e Lincoln (2003), a pesquisa qualitativa é um conjunto de práticas interpretativas que direcionam e representam o universo estudado. Sendo assim, as histórias de vida foram analisadas, de forma flutuante, à luz das teorias sobre gênero, masculinidades e homossexualidade, além do aporte das representações sociais.

\section{Apresentação e análise dos dados}

As maneiras pelas quais os entrevistados negociam as demandas da masculinidade e a homossexualidade são diversas e individualizadas, encontrando cada sujeito formas de viver a partir de suas particularidades. O primeiro grupo de depoimentos foi agrupado a partir de referências a ser homossexual e revelar-se como tal. 


\section{Ser e revelar-se gay}

Alguns dos entrevistados revelaram a homossexualidade para família e amigos próximos, mas não no círculo profissional; outros, em especial os mais velhos, nunca conversam acerca da sexualidade no ambiente familiar; e há, ainda, alguns que vivem abertamente sua homossexualidade nos diversos âmbitos da vida, o que confirma os achados de Irigaray (2007). A decisão de revelar ou não a homossexualidade apareceu na fala dos entrevistados como algo que poderia aproximar ou afastar pessoas. Ao mesmo tempo em que sentiram que os amigos e familiares poderiam julgá-lo mal ou discriminá-lo, o Entrevistado 1 optou por contar à mãe e amigos próximos para evitar mentiras sobre suas saídas com outros homens. No ambiente de trabalho, alguns entrevistados revelaram a homossexualidade apenas para colegas mais próximos, enquanto outros o fizeram de maneira ampla e aberta. Um dos entrevistados optou por apresentar o companheiro aos colegas de trabalho em uma festa da empresa para, ao mesmo tempo, evitar comentários indiretos, e ter a sensação de viver plenamente:

Eu não tenho como dormir com uma pessoa e depois chegar pros meus colegas [e dizer] eu não durmo com fulano, ou que eu moro sozinho, não tenho como, até porque são pessoas que vão vir aqui em casa e vão acabar comentando com os demais. (E11)

No processo de "sair do armário", estudado por Irigaray (2007), a maioria dos homens gays assumia apenas em parte a sua orientação sexual, pois viviam como homossexuais abertamente entre seus amigos e familiares, mas não em seus ambientes de trabalho, nos quais buscavam subterfúgios para não serem descobertos. Apenas uma minoria vivia sua homossexualidade de maneira totalmente assumida. Porém, mesmo entre estes, poucos eram os que se sentiam confortáveis para levar o parceiro a participar de eventos sociais ligados ao trabalho. Este desconforto possivelmente se deve ao fato de a representação social de si próprio ser desviante, distinta do que se esperaria de um homem. Além das representações sociais, existe o preconceito, o que leva a condições favoráveis para que se omita a orientação sexual no ambiente profissional, o que, mesmo assim, pode levar a especulações sobre a orientação sexual.

Sobre dúvidas dos colegas de trabalho quanto ao entrevistado ser ou não ser gay, Louro (2000) comenta que no convívio social há uma necessidade de "ler e interpretar" o outro, ou seja, enquadrá-lo em categorias predefinidas a partir da aparência do seu corpo. A marca ou categoria primordial neste sentido é o gênero, que define aos olhos dos demais se este é um sujeito masculino ou feminino, mas também carrega consigo as expectativas que compõe os papéis de homens e mulheres. Para a autora, especialmente neste campo a incerteza e a fluidez são difíceis de aceitar, o que é ilustrado pelo próximo depoimento:

\footnotetext{
Eu sempre tive um comportamento muito sério, muito na minha, né? Nunca fui, assim, muito expansivo, e como eu tinha sido casado, tinha filhos, acho que isso gerava uma certa dúvida, né? (...) E o problema que às vezes, acontecia, era de uma colega de trabalho se interessar por mim. E isso, acho que numas três empresas aconteceu, e era muito difícil de eu saber lidar com isso (...) as coisas ficavam tão escancaradas, e isso que era o pior de tudo (...) Não escondiam esse interesse por mim, e que todo mundo na empresa sabia. E aí, eu era cobrado. 'Tá, mas como é que tu não pega e não leva...?', 'Não vai fazer nada?' Porque a maioria desses casos acabam no motel. (...) Tinha que ficar tirando o corpo fora... E, pra eles, eu era um hétero. (E2)
}

A discrição do comportamento do entrevistado 2 não impediu de ele ter sido considerado atraente por outros homossexuais em organizações nas quais trabalhou, o que para ele se tornou um problema à medida que implicava, por um lado, dúvidas de seus colegas quanto à sua heterossexualidade que se desdobravam em provocações para que correspondesse às investidas, e, por outro, ter de sair de "campo neutro", do conforto relativo da aparência de heterossexual, já que o interesse dos outros gays era justificado pela possibilidade de ser eventualmente correspondido, já que ele próprio era homossexual. 


\title{
Claudia Sirangelo Eccel, Luiz Alex Silva Saraiva e \\ Alexandre de Pádua Carrieri
}

Além disso, o receio de ser tachado de gay levou-o a evitar aproximação com um colega de trabalho efeminado:

\begin{abstract}
Teve uma empresa em que eu trabalhei em que houve, um certo comentário porque um cara dessa empresa era muito meu amigo, e ele era, ele é homossexual. E, ao mesmo tempo que eu não me sentia à vontade, às vezes, de estar com ele, porque eu sabia que as pessoas estavam olhando e isso ia gerar comentário, eu não achava certo eu tratar ele de uma forma dentro da empresa, assim, meio que ignorar, sabendo que a nossa relação era de amizade... Nós éramos muito amigos, assim. Então, sabe? Era aquele conflito. (...) E, aos poucos, eu fui tentando encarar isso, assim, sabe? Enfrentar. Mas eu sabia que como eu tava lá dentro da empresa, de que eu e ele teríamos alguma coisa. (E2)
\end{abstract}

A busca de alcance da heteronormatividade sugere, a julgar por este depoimento, inclusive o tipo permitido de relacionamento entre homens no ambiente de trabalho. Se o colega é efeminado, por exemplo, não pode ser amigo de um "macho", devendo seus contatos se restringir ao estritamente necessário. 0 entrevistado revela desconforto ao estar em sua companhia não pelo que o colega homossexual representa na sua vida pessoal, mas pelo olhar dos outros, que avaliam e criticam este tipo de aproximação entre colegas com orientações sexuais aparentemente diferentes. Este desconforto caracterizou um conflito pessoal a partir das diferenças de relacionamento entre os dois dentro e fora da empresa, algo que o entrevistado reconheceu e se propôs a enfrentar, o que implicou representar a si próprio de maneira distinta do colega para lidar com o preconceito.

\section{Autoimagem e preconceito}

O processo de lidar com a questão da homossexualidade passa em algum momento, necessariamente, por encarar a si próprio como homossexual, o que pode ser acompanhado por sentimentos de ambigüidade na auto-aceitação, como no seguinte depoimento:

\footnotetext{
Eu, a única coisa que eu recrimino é quando tu agrides outros, ou qualquer... Não só ser humano. Qualquer outra forma de vida, assim, que... pra mim, pecado é isso, sabe? Transgredir as leis do universo. Isso é pecado pra mim. É aquilo que se faz contra as leis do universo, as coisas... Aí, a homossexualidade significa transgredir? Não. Não é uma coisa normal isso. Fazer o quê? Tem que enfrentar isso que... Quer dizer, se um dia for uma doença: 'ah, descobriram que é uma doença'. Bom, se fizeram um remédio pra aquilo lá, pra curar, como se fosse uma vacina pr'aquilo, qualquer coisa, se é que se chegar a esse ponto, né? Mas não é. É um, talvez, é um distúrbio. Talvez seja. Eu acho que é um distúrbio, né? (E3)
}

Este entrevistado assume uma postura imprecisa a respeito da sua própria representação social, uma vez que, por um lado, diz ter se aceitado e acredita que a homossexualidade não significa transgressão, e repudia qualquer forma de agressão, associando-as a pecados; entretanto, por outro, sugere que pensa não se tratar de um aspecto normal, e associa-a hipoteticamente a uma doença, a um distúrbio, para o qual eventualmente seria possível um remédio ou vacina. 0 discurso médico acerca do normal/desviante ou saúde/doença foi, durante muito tempo, utilizado para cercear a homossexualidade e significá-la como um desvio a ser combatido (GÓIS, 2004). Embora mudanças já tenham sido impressas no discurso médico e outros saberes tenham proposto formas alternativas de significar a sexualidade, a justificativa biológica da reprodução ainda aparece como um indício da anormalidade das práticas não heterossexuais (LOURO, 2000), o que é relevante no caso de alguns entrevistados, conforme o depoimento anterior ratifica.

Entretanto, muitas vezes, a diferença nas representações sociais é tamanha, e a rejeição, tão grande, a ponto de alguns entrevistados sequer se reconhecerem sob a mesma "rubrica" de gays efeminados ou que se manifestam abertamente: 
No meu caso, ser gay é ser um pouco mais sensível do que outras pessoas (...) ser gay é um estado de espírito muito bonito. É uma coisa muito bonita. Não é o colorido do arco-íris da bandeira gay, mas a gente vê a vida de outra forma. (...) Então, pra mim, eu acho que o gay, o gay que não é um gay, extrovertidamente, que vá agredir a sociedade, como muitos estão fazendo... Então, tem essa sensibilidade, essa particularidade, sabe? Esse toque mais emotivo, mais, sabe? Mais, mais humano, né? Que, às vezes, até um hétero pode ser, mas ele mascara, né? (E6)

Hoje, eu, com 56 anos, eu sou o fruto desses (...) anos, do que a sociedade me moldou, do que eu achava que devia ser, o quanto eu devia ceder pra um lado ou pro outro... (...) Eu também, eu não teria nunca como ser, tipo assim, ah, um travesti, entendeu? (...) A minha homossexualidade não é essa. E eu sempre fui um cara que joguei bola, fazia as coisas tudo de um homem. Só que tinha atração por homem. Então (...) eu nunca deixei de fazer as coisas de homem, o que dizem que homem faz, que é o que na sociedade o que homem faz. (E3)

Os dois depoimentos anteriores se aproximam em um aspecto: nas representações diferenciadas sobre "o que sou como homossexual" versus o que os outros gays são (efeminados, em particular). No primeiro caso, sua representação de homossexualidade é essencialmente ligada à sensibilidade, a uma forma de ver o mundo com mais emotividade, mas é um contexto de que não fazem parte os outros gays, os que, por sua extroversão, agridem a sociedade. 0 segundo depoimento coloca diferentes expressões homossexuais, como a de travestis, em um patamar distinto do que o que representa como adequado para ele próprio. 0 que justifica essa diferenciação é o fato de ele, como gay, sempre ter feito "coisas de homem", sugerindo que os homossexuais efeminados não o fazem, e, portanto, não podem ser representados de maneira semelhante, e, tampouco, pertencer à mesma "categoria", um processo de diferenciação.

\section{Masculinidade e preconceito}

Ser diferente da masculinidade hegemônica e perceber-se como tal conduz, no caso dos entrevistados, a um lugar delicado. Os depoimentos sobre a masculinidade revelam uma espécie de homofobia entre os próprios homossexuais, que discriminam e desvalorizam aqueles efeminados e escandalosos. Welzer-Lang (2004) afirma ainda que, em uma mesma sociedade, dominantes e dominados não têm o mesmo acesso a informações e, portanto, não compartilham dos possíveis sentidos, linguagens e formas da dominação, o que faz com que, muitas vezes, divirjam a respeito do que é ser dominado e do que é dominar. Assim, a própria condição de ser dominado impõe que, em algum nível, não se reconheça a própria dominação (CORRÊA, 1998). Welzer-Lang (2004) exemplifica por meio de mulheres agredidas que não percebiam como violência atos que o homem agressor confessava. Podemos discutir tal elemento a partir da violência e dominação simbólicas que se colocam acerca das maneiras certas de viver como homem que remetem à noção de masculinidade hegemônica. Muitas vezes esta representação de masculinidade hegemônica compartilhada entre os entrevistados se coloca nas maneiras como falam de si ou de sua sexualidade:

Eu sou um camarada discreto, de nível superior, mestrado, trabalho com engenharia. (E10)

Ser gay é, apenas, ter atração por outro homem. 0 resto é tudo igual a não ser gay. (E1)

No primeiro depoimento, o entrevistado, ao sugerir que é homossexual invocando a discrição, uma característica comportamento, imediatamente menciona sua formação superior diferenciada, e sua área de trabalho, a engenharia, um domínio predominantemente masculino. De certa forma, é como se tratasse de uma validação de quem ele se percebe, do ponto de vista educacional e profissional. 0 segundo depoimento, ao definir o homossexual, esvazia e despolitiza o conceito, reduzindo-o à esfera da atração sexual, e silenciando sobre os aspectos relacionados à afetividade, à diferença, ao preconceito, à vida do gay em sociedade, enfim. 


\section{Claudia Sirangelo Eccel, Luiz Alex Silva Saraiva e \\ Alexandre de Pádua Carrieri}

Existem diversas formas de viver como gay e as identidades sexuais não são rótulos estanques (SEFFNER, 2003; ROLNIK, 1996), de maneira que existem inúmeras diferenças entre as vivências homossexuais. Embora se trate de masculinidades subordinadas comparadas ao parâmetro da representação de masculinidade hegemônica (e heteronormativa), mesmo entre as masculinidades homossexuais é possível perceber desníveis de poder e legitimação. A homofobia, discriminação de pessoas em função de sua sexualidade, se faz presente não apenas por parte dos heterossexuais, mas também entre homossexuais. Areda (2006) percebeu a mesma questão do preconceito de homens homossexuais para com outros homens de postura efeminada na cidade de Brasília. Segundo o autor, mesmo em meios homossexuais existe a preocupação dos homens em se afirmarem como machos, o que se aproxima da heteronormatividade, conforme o seguinte depoimento de um entrevistado, que tinha receio de se assumir gay:

Porque eu achava que eu ia perder o respeito das pessoas. E eu não queria... $\mathrm{Na}$ realidade, eu não queria ser motivo de chacota, entendeu? Eu não queria que (...) ficassem falando do mim ou me julgando. Enfim... E, talvez, um pouco, acho que no fundo, assim, o fato de ser homossexual, eu sempre tive muito preconceito de ser homossexual, também. Levei muito tempo pra entender e me aceitar como homossexual. Então, eu acho que o preconceito também, partiu muito de mim, por eu não aceitar essa minha natureza e não queria que os outros me vissem de forma, assim, ah, inferior, ou motivo de chacota. (...) Cara afeminado. Eu tenho preconceito com isso, às vezes. Talvez seja feio, (...) mas eu tenho preconceito. (E2)

Ao assumir seu preconceito em geral em relação a homossexuais, e, mais especificamente, em relação a efeminados, este entrevistado inferioriza estes sujeitos a partir da reprodução da heteronormatividade. É porque existe um jeito "certo" de ser homem que permite definir e distinguir níveis diferenciados de masculinidade, sendo ao mais próximos do padrão os dominantes, e os demais, subordinados. Uma interpretação possível acerca deste fato é a incorporação de padrões próprios da masculinidade hegemônica, que fazem com que estes homens considerem que é preciso ter estilos de comportamentos tipicamente masculinizados, seja em função de seus valores individuais, seja devido à educação que receberam. Além disso, Paula (2006) sugere que as representações de sujeitos homossexuais veiculadas na mídia contribuem para a estigmatização e cristalização de preconceitos contra gays efeminados, quando os retratam de maneira estereotipada e caricatural.

Ademais, há percepção de que ser gay e ter um comportamento efeminado é pejorativo e agressivo para a sociedade, o que não contribuiria para uma pacífica convivência entre gays e heterossexuais:

Eu sou uma pessoa igual, normal, igual a todas as outras. Não tem que ter nada diferente, não tem que sair na rua alardeando e pedindo respeito. Eu não preciso disso. Eu trabalho e eu me sustento e eu pago meus impostos como todo mundo, aquele discurso, mas, na realidade, é isso mesmo. Eu não preciso estar reivindicando e, onde eu trabalho, naquilo que eu faço, eu faço muito bem feito, eu sei disso. Não posso ser modesto nesse ponto também, sabe? Eu faço, no que eu me proponho, eu faço muito bem feito. Sou uma pessoa determinada, acho que consegui muita coisa na minha vida. De onde eu vim, como eu te falei, uma família muito humilde. Então, não tem porque ser considerado diferente. Eu quero ser tratado como todo mundo é tratado. Entendeu? Sem sair falando o que eu faço na cama ou com quem, né? Então, eu não me identifico absolutamente em nada com passeata, manifesto... Sou contra esse tal de casamento gay. Sou contra essa gente que fica se manifestando afetivamente nas ruas, que tu vê que é agressivo. Sabe? Não combina, tá entendendo? Não combina. A sociedade não tá preparada pra isso e eu acho também que não é isso que vai... Que vai te trazer benefícios ou que vai te fazer bem. Assim, eu não preciso estar com o meu companheiro na rua, de mão dada, abraçado ou beijando. Não tem por quê, né? (E2) 
Este depoimento representa de forma distinta a questão da homossexualidade, pois sugere que para ser aceito, tratado de forma igual às outras pessoas, é preciso evitar atritos com a sociedade, mantendo-se na esfera da "discrição". Os conflitos a que o entrevistado se refere são ligados à visibilização do homossexual e de sua afetividade, e à demanda por direitos. Seria este silêncio do ponto de vista social um caminho para a aceitação social?

\section{Considerações finais}

Neste artigo nosso foco é discutir como operam as representações sociais de masculinidade, a autoimagem e o preconceito entre os homens homossexuais, o que foi feito mediante uma pesquisa qualitativa baseada em entrevistas individuais na cidade de Porto Alegre junto a 13 homens, selecionados em virtude de já terem, ao longo de suas histórias de vida, passado por situações de assédio moral no trabalho.

Os principais resultados encontrados revelam a ambigüidade da masculinidade entre gays. Os que se aproximam do ideal da masculinidade dominante representam a si próprios de forma diferenciada em relação aos que demonstram ou lutam pela homossexualidade abertamente, sugerindo de que se trata de algo agressivo à sociedade - devendo os gays, portanto, para ter direitos, serem minimamente masculinos e discretos. Ficar à margem da sociedade, preservando o silêncio para eles parece ser o meio pelo qual os gays conseguiriam mais espaço. Além de embutir uma posição política - a da omissão - este posicionamento tem a ver com autopreservação, uma vez que este grupo não é imediatamente reconhecido como tal, e, possivelmente por conta disso, não aprova uma estratégia de exposição e de luta por direitos pelos homossexuais efeminados.

Ao mesmo tempo, as representações em sua maior parte distinguem o que é ser gay do que é ser heterossexual, situando, implicitamente, o homossexual em um patamar diferenciado de masculinidade por não ser "igual" aos "machos". Da mesma forma como este fenômeno ocorre, em geral, na diferenciação entre heterossexuais e homossexuais, sendo dominados estes pelos padrões hegemônicos de masculinidade definidos por aqueles, acontece, em particular, entre gays não efeminados e efeminados, sendo estes considerados inferiores, em termos de masculinidade, em relação àqueles. Esta espécie de hierarquia de masculinidades confirma as proposições e os resultados de pesquisas de Welzer-Lang (2004) e de Connell (1995).

Confirmamos o pressuposto de que os próprios homossexuais, sendo alvo de discriminação, também adotam práticas discriminatórias em relação a segmentos específicos de homossexuais, uma espécie de reprodução socialmente legitimada da discriminação. 0 mote é o mesmo: o que é diferente precisa ser avaliado, rotulado, hierarquizado, e colocado de lado, a fim de não ferir a heteronormatividade, mesmo em se tratando de gays.

As principais implicações deste estudo se referem à compreensão das representações sociais, que permitem penetrar no universo simbólico de grupos sociais, esclarecendo como se constroem conceitos grupais e respostas, no nível comportamental, a tais conceitos. Quando se tem em mãos um material como este, que trata especificamente de um dos grupos mais discriminados da sociedade, entender como eles se sentem e reagem, no âmbito social e das organizações, é muito relevante, não apenas porque a diversidade hoje integra a pauta das esferas pública, privada e do terceiro setor, mas porque permite visualizar como funciona a engrenagem social de cerceamento e as estratégias utilizadas pelos gays para burlá-la.

Sob a ótica das organizações, um estudo como este deixa questões consideráveis a serem respondidas, inclusive sob a forma de pesquisas que complementem e ampliem o escopo deste artigo: qual o espaço efetivo para as diferenças, sejam elas quais forem? O objeto aqui são 


\section{Claudia Sirangelo Eccel, Luiz Alex Silva Saraiva e \\ Alexandre de Pádua Carrieri}

homens homossexuais, que muitas vezes "atuam" como heterossexuais para não serem discriminados, o que tem custos psicológicos elevados, principalmente se considerarmos aspectos como a autoestima e a autoimagem. Mas o que dizer das mulheres? Das pessoas com deficiência? Dos negros? Dos mais velhos? Em síntese: qual o espaço efetivo para o diferente do hegemônico no contexto organizacional?

\section{Referências}

AREDA, F. Ser gay e a possibilidade de não ser homem. In: SEMINÁRIO INTERNACIONAL FAZENDO GÊNERO: GÊNERO E PRECONCEITO, VII, 2006, Florianópolis. Anais... Florianópolis: UFSC, 2006.

AZEVEDO, C. S. Liderança e processos intersubjetivos em organizações públicas de saúde. Ciência \& Saúde Coletiva, Rio de Janeiro, v. 7, n. 2, p. 349-361, 2002.

BASTOS, E. M.; PINHEIRO, M. S.; LIMA, T. C. B. Orientação sexual e inclusão: um estudo de caso em organização varejista de Fortaleza. In: CONGRESSO BRASILEIRO DE ESTUDOS ORGANIZACIONAIS, I, 2013, Fortaleza. Anais... Fortaleza: SBEO, 2013.

BICALHO, R. A.; CAPRONI NETO, H. L. Análise das violências simbólicas vivenciadas por indivíduos transgêneros. In: ENCONTRO ANUAL DA ASSOCIAÇÃO NACIONAL DE PÓSGRADUAÇÃO E PESQUISA EM ADMINISTRAÇÃO, XXXVI, 2012, Rio de Janeiro. Anais... Rio de Janeiro: ANPAD, 2012.

BICALHO, R. A.; DINIZ, A. P. R. Violência simbólica e homossexualidade: um estudo em capitais. In: ENCONTRO ANUAL DA ASSOCIAÇÃO NACIONAL DE PÓS-GRADUAÇÃO E PESQUISA EM ADMINISTRAÇÃO, XXXIII, 2009, São Paulo. Anais... São Paulo: ANPAD, 2009.

BOURDIEU, P. A dominação masculina. Educação e Realidade, Porto Alegre, v. 20, n. 2, p. 133184 jul./dez. 1995.

CAPPELLE, M. C. A.; BRITO, M. J.; MELO, M. C. O. L; VASCONCELOS, K. A. A produção científica sobre gênero na administração: uma meta-análise. In: ENCONTRO ANUAL DA ASSOCIAÇÃO NACIONAL DE PÓS-GRADUAÇÃO E PESQUISA EM ADMINISTRAÇÃO, XXX, 2006, Salvador. Anais... Salvador: ANPAD, 2006.

CAPRONI NETO, H. L.; BRETAS, P. F. F.; SARAIVA, L. A. S.; SILVA, A. N. Desenhando a vivência: um estudo sobre sexualidade, tabu e trabalho de homens gays. In: ENCONTRO ANUAL DA ASSOCIAÇÃO NACIONAL DE PÓS-GRADUAÇÃO E PESQUISA EM ADMINISTRAÇÃO, XXXVIII, 2014, Rio de Janeiro. Anais... Rio de Janeiro: ANPAD, 2014.

CARRIERI, A. P.; AGUIAR, A. R. C.; DINIZ, A. P. R. Reflexões sobre o indivíduo desejante e o sofrimentono trabalho: o assédio moral, a violência simbólica e o movimento homossexual. Cadernos EBAPE.BR, Rio de Janeiro, v. 11, n. 1, p. 165-180, mar. 2013.

CARRIERI, A. P.; SOUZA, E. M.; AGUIAR, A. R. C. Trabalho, violência e sexualidade: estudo de lésbicas, travestis e transexuais. Revista de Administração Contemporânea, Curitiba, v. 18, n. 1, p. 78-95, jan./fev. 2014.

CAVEDON, N. R; FERRAZ, D. L. S. Representações sociais e estratégia em pequenos comércios. RAE eletrônica, São Paulo, v. 4, n. 1, jan/jun. 2005.

CONNELL, R. W. Masculinities and globalization. Men and Masculinities, London, v. 1, n. 1, p. 323, July 1998. 


\section{MASCULINIDADE, AUTOIMAGEM E PRECONCEITO EM REPRESENTAÇÕES SOCIAIS DE HOMOSSEXUAIS}

CONNELL, R. W. Políticas da masculinidade. Educação e Realidade, Porto Alegre, v. 20, n. 2, p. 185-206, jul./dez. 1995.

CORRÊA, M. L. A modernização na indústria têxtil e os condicionantes da formação profissional. Trabalho \& Educação, Belo Horizonte, n. 3, p. 161-184, jan./jul. 1998.

COSTA, J. S. M.; CHAVES, M. M. Assistência humanizada e estrutura organizativa: a necessária interface. a experiência do grupo de trabalho de humanização em um hospital público de Belo Horizonte. In: ENCONTRO ANUAL DA ASSOCIAÇÃO NACIONAL DE PÓS-GRADUAÇÃO E PESQUISA EM ADMINISTRAÇÃO, XXVIII, 2004, Curitiba. Anais... Curitiba: ANPAD, 2004.

DINIZ, A. P. R; CARRIERI, A. P.; GANDRA, G.; BICALHO, R. A. Políticas de diversidade nas organizações: as relações de trabalho comentadas por trabalhadores homossexuais. Economia \& Gestão, Belo Horizonte, v. 13, n. 31, p. 93-114, jan./abr. 2013

ECCEL, C. S.; FLORES-PEREIRA, M. T. A inserção da diversidade homossexual em uma livraria de shopping center: um estudo crítico. In: ENCONTRO ANUAL DA ASSOCIAÇÃO NACIONAL DE PÓSGRADUAÇÃO E PESQUISA EM ADMINISTRAÇÃO, XXXII, 2008, Rio de Janeiro. Anais... Rio de Janeiro: ANPAD, 2008.

GÓIS, J. B. H. Desencontros: as relações entre os estudos sobre a homossexualidade e os estudos de gênero no Brasil. In: CARVALHO, M. J. S.; ROCHA, C. M. F. (Org.). Produzindo gênero. Porto Alegre: Sulina, 2004.

HERZLICH, C. A problemáticas das representações sociais e sua utilidade no campo da doença. Physis: Revista de Saúde Coletiva, Rio de Janeiro, v. 15 (suplemento), p. 57-70, 2005.

IRIGARAY, H. A. R. Identidades sexuais não-hegemônicas: a inserção de travestis e transexuais no mundo do trabalho sob a ótica queer. In: ENCONTRO DE ESTUDOS ORGANIZACIONAIS, VI, 2010, Florianópolis. Anais... Florianópolis: ANPAD, 2010.

IRIGARAY, H. A. R. Estratégia de sobrevivência dos gays no ambiente de trabalho. In: ENCONTRO ANUAL DA ASSOCIAÇÃO NACIONAL DE PÓS-GRADUAÇÃO E PESQUISA EM ADMINISTRAÇÃO, XXXI, 2007, Rio de Janeiro. Anais... Rio de Janeiro: ANPAD, 2007.

IRIGARAY, H. A. R.; SARAIVA, L. A. S.; CARRIERI, A. P. Humor e discriminação por orientação sexual no ambiente organizacional. Revista de Administração Contemporânea, Curitiba, v. 14, n. 5, p. 890-906, set./out. 2010.

LIMA JÚNIOR, J. H. V.; ÉSTHER, A. B. Transições, prazer e dor no trabalho de enfermagem. Revista de Administração de Empresas, São Paulo, v. 41, n. 3, p. 20-30, jul./set. 2001.

LOURO, G. L. Corpo, escola e identidade. Educação e Realidade, Porto Alegre, v. 25, n. 2, p. 5976, jul./dez. 2000.

MATTOS, R. M.; FERREIRA, R. F. Quem vocês pensam que elas são? Representações sobre as pessoas em situação de rua. Psicologia \& Sociedade, Porto Alegre, v. 16, n. 2, p. 47-58, maio/ago. 2004.

OLIVEIRA, F. F.; DUARTE, C. P. Discurso dos professores e professoras de educação física sobre o relacionamento de meninos e meninas. In: SEMINÁRIO INTERNACIONAL FAZENDO GÊNERO: GÊNERO E PRECONCEITO, 7, 2006, Florianópolis. Anais... Florianópolis: UFSC, 2006.

PARKER, R. Empoderamento erótico e cidadania sexual para homens que fazem sexo com homens e tribos afins. In: RIOS, L. F; ALMEIDA, V.; PARKER, R.; PIMENTA C.; TERTO JUNIOR, V. (Org.). Homossexualidade: produção cultural, cidadania e saúde. Rio de Janeiro: Associação Brasileira Interdisciplinar de AIDS, 2004. 
PAULA, P. S. R. A representação da homossexualidade nos periódicos Babado e Folha de São Paulo. In: SEMINÁRIO INTERNACIONAL FAZENDO GÊNERO: GÊNERO E PRECONCEITO, 7, 2006, Florianópolis. Anais... Florianópolis: UFSC, 2006.

PELUSO, M. L. O potencial das representações sociais para a compreensão interdisciplinar da realidade: geografia e psicologia ambiental. Estudos de Psicologia, Natal, v. 8, n. 2, p. 321-327, 2003.

PEREIRA, C. A. M. 0 impacto da AIDS, a afirmação da 'cultura gay' e a emergência do debate em torno do 'masculino' - fim da homossexualidade? In: RIOS, L. F; ALMEIDA, V.; PARKER, R.; PIMENTA C.; TERTO JUNIOR, V. (Org.). Homossexualidade: produção cultural, cidadania e saúde. Rio de Janeiro: Associação Brasileira Interdisciplinar de AIDS, 2004.

PEREIRA, B.; AYROSA, E.; OJIMA, S. Consumo entre gays: compreendendo a construção da identidade homossexual através do consumo. In: ENCONTRO ANUAL DA ASSOCIAÇÃO NACIONAL DE PÓS-GRADUAÇÃO E PESQUISA EM ADMINISTRAÇÃO, XXIX, 2005, Brasília. Anais... Brasília: ANPAD, 2005.

ROBICHAUD, A.; DAVEL, E. Influência, sexualidade e representações familiares nas organizações. Organizações \& Sociedade, Salvador, v. 9. n. 24, p. 53-74, maio/ago. 2002.

ROLNIK, S. Guerra dos gêneros \& guerra aos gêneros. Disponível em: http://www.rizoma.net/. 1996. Acesso em: 22 fev. 2009.

SANTOS, L. H. S. D. Educação e pesquisa de práticas sexuais de risco. In: RIOS, L. F; ALMEIDA, V.; PARKER, R.; PIMENTA C.; TERTO JUNIOR, V. (Org.). Homossexualidade: produção cultural, cidadania e saúde. Rio de Janeiro: Associação Brasileira Interdisciplinar de AIDS, 2004.

SARAIVA, L. A. S. Além dos estigmas profissionais. In: FREITAS, M. E.; DANTAS, M. (Org.). Diversidade sexual e trabalho. São Paulo: Cengage Learning, 2011. p. 149-168.

SARAIVA, L. A. S.; SILVEIRA, L. G. A. Representações sociais do trabalho entre profissionais de um hospital de Minas Gerais. Revista de Gestão USP, São Paulo, v. 14, n. 2, p. 77-91, abr./jun. 2007.

SEFFNER, F. Derivas da masculinidade: representação, identidade e diferença no âmbito da masculinidade bissexual. 2003. 260 f. Tese (Doutorado em Educação) - Faculdade de Educação, Universidade Federal do Rio Grande do Sul, Porto Alegre, 2003.

SIQUEIRA, M. V. S.; ZAULI-FELLOWS, A. Diversidade e identidade gay nas organizações. In: ENCONTRO DE ESTUDOS ORGANIZACIONAIS, IV, 2006, Porto Alegre. Anais... Porto Alegre: ANPAD, 2006.

SIQUEIRA, M. V. S.; SARAIVA, L. A. S.; CARRIERI, A. P.; LIMA, H. K. B.; ANDRADE, A. J. A. Homofobia e violência moral no trabalho no Distrito Federal. Organizações \& Sociedade, Salvador, v. 16, n. 50, p. 447-461, jul./set. 2009.

TIRELLI, C. Entretenimento noturno para casais gays: um estudo exploratório. 2006. $87 \mathrm{f}$. Trabalho de conclusão de curso (Bacharelado em Administração) - Escola de Administração, Universidade Federal do Rio Grande do Sul, Porto Alegre, 2006.

WELZER-LANG, D. Os homens e o masculino numa perspectiva das relações sociais de sexo. In: SCHPUN, M. R. (Org.). Masculinidades. São Paulo/Santa Cruz do Sul: Boitempo/Edunisc, 2004. 